\title{
Corneal endothelial cell density and morphology in Phramongkutklao Hospital
}

\author{
Narumon Sopapornamorn' \\ Manapon Lekskul' \\ Suthee Panichkul ${ }^{2}$ \\ 'Department of Ophthalmology, \\ Phramongkutklao Hospital, Bangkok, \\ Thailand; ${ }^{2}$ Department of Obstetrics \\ and Gynecology, Phramongkutklao \\ College of Medicine, Bangkok, \\ Thailand
}

\begin{abstract}
Objective: To describe the corneal endothelial density and morphology in patients of Phramongkutklao Hospital and the relationship between endothelial cell parameters and other factors. Methods: Four hundred and four eyes of 202 volunteers were included. Noncontact specular microscopy was performed after taking a history and testing the visual acuity, intraocular pressure measurement, Schirmer's test and routine eye examination by slit lamp microscope. The studied parameters included mean endothelial cell density (MCD), coefficient of variation (CV), and percentage of hexagonality.

Results: The mean age of volunteers was 45.73 years; the range being 20 to 80 years old. Their MCD (SD), mean percentage of CV (SD) and mean (SD) percentage of hexagonality were $2623.49(325)$ cell $/ \mathrm{mm}^{2}, 39.43(8.23) \%$ and $51.50(10.99) \%$, respectively. Statistically, MCD decreased significantly with age $(\mathrm{p}<0.01)$. There was a significant difference in the percentage of $\mathrm{CV}$ between genders. There was no statistical significance between parameters and other factors.

Conclusion: The normative data of the corneal endothelium of Thai eyes indicated that, statistically, MCD decreased significantly with age. Previous studies have reported no difference in $\mathrm{MCD}$, percentage of $\mathrm{CV}$, and percentage of hexagonality between gender. Nevertheless, significantly different percentages of $\mathrm{CV}$ between genders were presented in this study.
\end{abstract}

Keywords: Corneal endothelial cell, parameters, age, gender, smoking, Thailand

\section{Background}

The cornea contains 5 layers. In the deepest layer, monolayer of corneal endothelial cell covers the posterior surface of descemet's membrane. Corneal endothelium is metabolically active $\left(\mathrm{Na}^{+}-\mathrm{K}^{+}\right.$pump) and responsible for keeping the corneal stroma in its usual hydrated state of 70\% water to prevent stromal edema (Krik 2005).

Nowadays specular microscope has made the in vivo evaluation of endothelium possible. It measures mean cell density (MCD), cell size variations (percentage of coefficient of variation [CV], polymegathism), and cell shape (polymorphism). The specular microscope has been used to establish and compare normative data for endothelium parameters among ethnic groups, as well as gender and age.

Due to the difference in endothelial parameters among various populations (Matsuda et al 1985; Rao et al 2000; Snellingen et al 2001; Kitagawa et al 2002; Padilla et al 2004; Hashemian et al 2006; Zoega et al 2006) the study of normative data of each population is important. This study described the endothelial cell density and morphology of normal Thai eyes in relation to age, gender, and some risk factors such as smoking, underlying disease, intraocular pressure (IOP), and Schirmer's test.

\section{Materials and methods}

The study population comprised 216 volunteers randomly selected from the visitors, outpatients, and staff of Phramongkutklao Hospital. Sample size was calculated using a 
minimum exceptional error (10\%) of SD from normal Indian cell density data (Rao et al 2000).

Subjects were submitted to medical history examination and excluded from the study if they presented history of intraocular surgery or ocular trauma, corneal opacity, glaucoma, dry eye, inflammatory eye disease like uveitis, diabetes mellitus, use of contact lens, and family history of corneal decompensation. Additionally, to investigate the unknown effect of underlying diseases (such as hypertension, allergy, etc) and eye drugs (such as antihistamine) on corneal endothelium, such underlying diseases and eye drugs were included in the present study. According to the exclusion criteria, 14 volunteers were excluded. A total of 404 eyes from 202 volunteers (aged 20 to 80 years) were examined. All the subjects enrolled in this study originated from Thailand. Their national ID card and hospital record presented their Thai race and Thai nationality. Subjects enrolled in the study signed an informed consent form, and this study was approved by the Ethical Committee for Human Research, Phramongkutklao Hospital.

After taking a patient history, which included age, gender, smoking, underlying disease, and use of eye drop drugs, visual acuity measurement by Snellen chart, noncontact ocular tension measurement, modified Schirmer's test 1 in 5 minutes, and slit-lamp biomicroscopy examination were examined. All volunteers underwent specular microscopy using a noncontact specular microscopy (SP2000: Topcon corporation, Japan). A single examiner performed all of the measurements. Corneal endothelial cell analysis was performed as follows: images from central cornea were taken of at least 50 contiguous cells and were manually marked with a mouse by the examiner for analysis by a built-in software program.

\section{Statistical analysis}

For statistical analysis, the SPSS program (version 11.5) was used. Baseline characteristics were calculated by descriptive statistics (eg, mean and standard deviation) and compared by using unpaired t-test for parametric data. Correlation between factors (age, gender, smoking, underlying disease, eye drop drug use, intraocular pressure, and Schirmer's test) and MCD, percentage of $\mathrm{CV}$ and percentage of hexagonality were calculated by Pearson correlation.

In studies of the corneal endothelial cell morphology, which could be affected by multiple factors, the multiple regression analysis was used. p-value less than 0.05 were considered as the significance.

\section{Results}

Characteristics of the subjects were shown in Table 1. 202 patients with a mean (SD) age of 45.73 (16.12) years old participated. Ninety patients $(44.6 \%)$ were male and one hundred and twelve patients (55.4\%) were female. The most visual acuity was 20/20 (36.6\%) and visual acuity range was 20/20 to light perception. Mean (SD) intraocular pressure was 13.76 (3.17) mmHg. Mean (SD) Schirmer's test was $8.09(6.13) \mathrm{mm}$.

Table 2 describes the total data of corneal endothelial cell density and morphology and the characteristics of the studied population in gender difference. Their MCD (SD), mean percentage of CV (SD) and mean (SD) percentage of hexagonality were $2623.49(325) \mathrm{cell} / \mathrm{mm}^{2}, 39.43(8.23) \%$ and 51.50(10.99)\%, respectively.

Results of mean MCD, mean percentage of $\mathrm{CV}$ and mean percentage of hexagonality in different age groups are listed in Table 3. MCD was statistically significantly decreased in relation to increasing age $(\mathrm{p}<0.01)$ (Figure 1$)$.

The correlation between parameters and others factors (Table 4) are shown: the p-value of each factor related with $\mathrm{MCD}$, percentage of $\mathrm{CV}$, and percentage of hexagonality. There were significant correlations between age and MCD,

Table I Characteristics of the subjects

\begin{tabular}{ll}
\hline General data & No. (\%) \\
\hline Gender & \\
Male & $90(44.6)$ \\
Female & $112(55.4)$ \\
Age (Year: mean \pm SD) & $45.73 \pm 16.12$ \\
Underlying disease & \\
Yes & $48(23.8)$ \\
No & $154(76.2)$ \\
Eye drop drug use & \\
Yes & $15(7.4)$ \\
No & $187(92.6)$ \\
Smoking & \\
Yes & $38(81.8)$ \\
No & $164(18.8)$ \\
Number of smoking (pack/day) & $10.61 \pm 7.87$ \\
(mean \pm SD) & \\
Smoking duration (Year: mean \pm SD) & $15.53 \pm 12.59$ \\
Now stop smoking & \\
Yes & $23(60.53)$ \\
No & $15(39.47)$ \\
Duration of stop smoking (year) & $10.57 \pm 10.79$ \\
Visual acuity (uncorrected) & \\
$20 / 20-20 / 50$ & $183(90.6)$ \\
$20 / 70-$ PL & $19(9.4)$ \\
Mean intraocular pressure & $13.76 \pm 3.17 \mathrm{mmHg}$ \\
Mean Schirmer's test & $8.09 \pm 6.13 \mathrm{~mm}$ \\
\hline
\end{tabular}


Table 2 Endothelial cell characteristics of the study population in different gender

\begin{tabular}{lllll}
\hline & Male & Female & p-value & Total \\
\hline No. of eyes & 180 & 224 & & 404 \\
Age (year) & $41.73 \pm 18.21$ & $48.94 \pm 13.46$ & 0.002 & $45.73 \pm 16.12$ \\
Cell density (cells $/ \mathrm{mm}^{2}$ ) & $2679.98 \pm 361.89$ & $2578.10 \pm 284.93$ & 0.002 & $2623.49 \pm 325.06$ \\
Cell size variability (\%) & $37.94 \pm 7.13$ & $40.62 \pm 8.86$ & 0.001 & $39.43 \pm 8.23$ \\
Hexagonality & $53.77 \pm 10.69$ & $49.68 \pm 10.92$ & $<0.001$ & $51.50 \pm 10.99$ \\
\hline
\end{tabular}

Notes: anpaired t-test.

Table 3 Endothelial cell characteristics of the study population in different age groups

\begin{tabular}{|c|c|c|c|c|}
\hline $\begin{array}{l}\text { Age group } \\
\text { (years) }\end{array}$ & No. of eyes & $\begin{array}{l}\text { Cell density } \\
\left(\text { cells } / \mathbf{m m}^{2}\right)^{a}\end{array}$ & $\begin{array}{l}\text { Cell size } \\
\text { variability (\%) }\end{array}$ & Hexagonality \\
\hline $20-30$ & 94 & $2799.02 \pm 260.44$ & $38.88 \pm 6.88$ & $54.4 \mathrm{I} \pm \mathrm{II} .57$ \\
\hline $31-40$ & 50 & $2744.60 \pm 236.85$ & $38.73 \pm 8.52$ & $50.86 \pm 9.11$ \\
\hline $4 I-50$ & 104 & $2642.66 \pm 304.55$ & $39.61 \pm 7.97$ & $50.02 \pm 10.85$ \\
\hline $51-60$ & 78 & $2553.12 \pm 266.88$ & $40.19 \pm 7.26$ & $49.84 \pm 11.48$ \\
\hline over 6I year & 78 & $2379.00 \pm 356.30$ & $39.53 \pm 10.59$ & $52.04 \pm 10.59$ \\
\hline
\end{tabular}

Notes: aMean $\pm \mathrm{SD}$.

and between age and percentage of hexagonality. Gender showed a significant correlation in $\mathrm{MCD}$, percentage of $\mathrm{CV}$ and percentage of hexagonality. Moreover, there is a significant correlation between Schirmer's test and percentage of hexagonality. However, no significant correlations between parameters and other factors such as intraocular pressure, smoking, underlying disease, and eye drop drug use were shown in this study.

The multiple regression analysis between parameters and univariate significant factors are showed in Table 5.

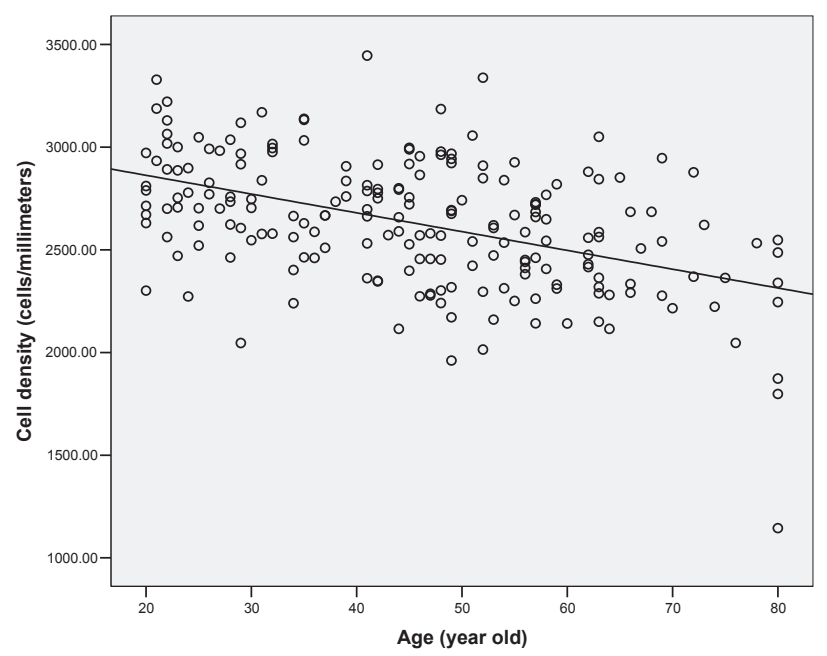

Figure I Correlation between MCD and age.
However, there is statistical significance only between age and $\mathrm{MCD}$, age and percentage of hexagonality, and gender and percentage of $\mathrm{CV}$.

\section{Discussion}

Endothelial cell analysis is important for corneal function and viability assessment. The clinical uses include the assessment of donor corneal endothelium, the effects of intraocular surgery and the essential in evaluating the safety of the first time intraocular or corneal surgical procedures and intraocular lens.

Many studies have been published on endothelial cell density and morphology in relation to age, gender, and ethnicity. Although it is clear that significant differences in corneal endothelial properties do exist among races and ethnic

Table 4 Correlation between parameters and other factors

\begin{tabular}{llll}
\hline Factors & MCD & \%CV & Hexagonality \\
\hline Age & 0.000 & 0.310 & 0.022 \\
Gender & 0.002 & 0.001 & 0.000 \\
Smoking & 0.759 & 0.972 & 0.875 \\
Underlying disease & 0.931 & 0.825 & 0.437 \\
Long term eye drug use & 0.213 & 0.227 & 0.507 \\
IOP & 0.881 & 0.510 & 0.825 \\
Schirmer's test & 0.079 & 0.127 & 0.012
\end{tabular}

Abbreviations: $M C D$, mean endothelial cell density; $C V$, coefficient of variation; IOP, intraocular pressure.

Notes: $\mathrm{p}$-value $<0.05$. 
Table 5 Multiple regression analysis between parameters and univariated significant factors

\begin{tabular}{|c|c|c|c|c|c|}
\hline & B & $E(B)$ & $\mathbf{t}$ & p-value & $95 \% \mathrm{Cl}$ \\
\hline \multicolumn{6}{|l|}{$\overline{M C D}$} \\
\hline constant & 3051.939 & & 50.689 & $<0.001$ & $2933.209,3170668$ \\
\hline age & -8.959 & -0.458 & -7.125 & $<0.001$ & $-11.438,-6.479$ \\
\hline gender & -26.593 & -0.042 & -0.654 & 0.514 & $-106.796,53.610$ \\
\hline \multicolumn{6}{|l|}{$C V$} \\
\hline constant & 37.936 & & 62.404 & $<0.001$ & 36.74I, 39.131 \\
\hline gender & 2.687 & 0.162 & 3.295 & 0.001 & $1.084,4.290$ \\
\hline \multicolumn{6}{|l|}{ HEXA } \\
\hline constant & 55.187 & & 19.138 & $<0.001$ & $49.50 I, 60.874$ \\
\hline age & -0.085 & 0.050 & -1.715 & 0.088 & $-0.184,0.013$ \\
\hline gender & -2.370 & -0.106 & -1.439 & 0.152 & $-5.619,0.878$ \\
\hline Schirmer's test & 0.152 & 0.076 & 1.047 & 0.296 & $-0.134,0.439$ \\
\hline
\end{tabular}

groups, normative data that is derived from the underlying population of each country is still necessary. This study reports endothelial cell data in Thai population.

Noncontact specular microscopy is used in many studies. Image capturing of the endothelium cells and calculation of cornea endothelial cells by a unique method does not require touching the cornea. This patented procedure eliminates the risk of transmitted infectious diseases and reduces potential physical injury to the eye. The disadvantage of this method is less control over patient eye movement.

The endothelium has been reported with confocal microscopy. Comparison of endothelial cell count density using confocal and contact specular microscopy was studied by Klais and colleagues (2003), no statistically significant difference of endothelial cell density between confocal and specular microscopy.

In our study, the endothelial cell parameters were within normal range. The results have shown that with increasing age, MCD and \% CV tended to decrease. There were conflicting reports about the relationship between gender and endothelial cell characteristics. Many studies have not found any statistical differences between them (Laing et al 1976; Hirst et al 1980; Matsuda et al 1985; Landesz et al 1995; AAO 1997; Hashemian et al 2006) as our data showed no differences between MCD, hexagonality, and gender. However we have found that females have a higher percentage of $\mathrm{CV}$ than males. As it was only one significant parameter, we could not assume that the female quality of corneal endothelium was less than that of males.

We did not find that smoking, underlying disease, eye drop drug usage, IOP, and Schirmer's test affected the corneal endothelium. Zoega and colleagues (2006) had studied the risk factors for cornea guttata and found that smoking more than 20 pack-years increased the risk of developing corneal guttata more than 2-fold but our study did not find correlation between them. This could be for two reasons. Firstly, there was no real significance. Secondly, our number of pack-years was less than the previous study so we did not find the difference.

While we collected the data, we found abnormal endothelial parameters like Fuchs' dystrophy. A 50 year old female

Table 6 Comparison of endothelial cell density

\begin{tabular}{|c|c|c|c|c|c|c|c|c|}
\hline \multirow[t]{2}{*}{$\begin{array}{l}\text { Age group } \\
\text { (Years) }\end{array}$} & \multicolumn{2}{|c|}{$\begin{array}{l}\text { Phramongkutklao } \\
\text { Hospital }\end{array}$} & \multicolumn{2}{|l|}{ India } & \multicolumn{2}{|l|}{ Japan } & \multicolumn{2}{|c|}{ America } \\
\hline & $\begin{array}{l}\text { No. of } \\
\text { eyes }\end{array}$ & $\begin{array}{l}\text { MCD } \\
\left(\text { cell } / \mathrm{mm}^{2}\right)^{a}\end{array}$ & $\begin{array}{l}\text { No. of } \\
\text { eyes }\end{array}$ & $\begin{array}{l}\text { MCD } \\
\left(\text { cell } / \mathrm{mm}^{2}\right)^{a}\end{array}$ & $\begin{array}{l}\text { No. of } \\
\text { eyes }\end{array}$ & $\begin{array}{l}\text { MCD } \\
\left(\text { cell } / \mathrm{mm}^{2}\right)^{a}\end{array}$ & $\begin{array}{l}\text { No. of } \\
\text { eyes }\end{array}$ & $\begin{array}{l}\text { MCD } \\
\left(\text { cell } / \mathrm{mm}^{2}\right)^{a}\end{array}$ \\
\hline $21-30$ & 94 & $2799 \pm 260$ & 104 & $2782 \pm 250$ & 18 & $3893 \pm 259$ & 11 & $2977 \pm 324$ \\
\hline $31-40$ & 50 & $2744 \pm 236$ & 96 & $2634 \pm 288$ & 10 & $3688 \pm 245$ & 6 & $2739 \pm 208$ \\
\hline $4 I-50$ & 104 & $2642 \pm 304$ & 97 & $2408 \pm 274$ & 10 & $3749 \pm 407$ & 11 & $2619 \pm 321$ \\
\hline $51-60$ & 78 & $2553 \pm 266$ & 98 & $2438 \pm 309$ & 10 & $3386 \pm 455$ & 13 & $2625 \pm 172$ \\
\hline $6 I-70$ & 50 & $2485 \pm 267$ & 88 & $243 I \pm 357$ & 6 & $3307 \pm 330$ & 8 & $2684 \pm 384$ \\
\hline$>70$ & 28 & $2189 \pm 416$ & 54 & $2360 \pm 357$ & 15 & $3289 \pm 313$ & 15 & $2431 \pm 339$ \\
\hline
\end{tabular}

Abbreviations: $M C D$, mean endothelial cell density; SD, standard deviation.

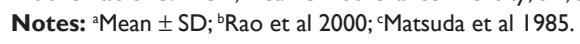


had been examined. Her right eye had MCD $1564.8 \mathrm{cell} / \mathrm{mm}^{2}$, CV 75.3\%, and hexagonality 26\%. Her left eye had MCD $1836.6 \mathrm{cell} / \mathrm{mm}^{2}, \mathrm{CV} 56.9 \%$, and hexagonality $40 \%$. The incidence of abnormal endothelial cell was calculated about $1: 202(0.5 \%)$.

We compared MCD with the previous studies and found the difference (Table 6). In our study, MCD was similar to the Indian population (Rao et al 2000) but less than the Japanese and American populations (Matsuda et al 1985).

\section{Conclusions}

The normative data of the corneal endothelium of Thai eyes indicated and confirmed that MCD was decreased with increasing age and there are statistically significant differences in polygonality between genders. Relationship between endothelial cell parameters and some factors like smoking, underlying disease, eye drop drug usage, IOP, and Schirmer's test were not found.

MCD in Thai population was similar to the Indian population compared with the previous studies. However, it was less than in the Japanese and American populations.

\section{Acknowledgment}

The authors would like to thank Dr. Praweena Sopapornamorn and Miss Worarachanee Imjaijitt for their valuable comments on this paper.

\section{References}

[AAO] American Academy of Ophthalmology. 1997. Corneal endothelial photography. Three-year revision. Ophthalmology, 104:1360-5.

Hashemian MN, Moghimi S, Fard MA. 2006. Corneal endothelial cell density and morphology in normal Iranian eyes. BMC Ophthalmol, 6:9.

Hirst LW, Ferris FL III, Stark WJ, et al. 1980. Clinical specular microscopy. Invest Ophthalmol Vis Sci, 19:2-4.

Kitagawa K, Kojima M, Sasaki H, et al. 2002. Prevalence of primary cornea guttata and morphology of corneal endothelium in aging Japanese and Singaporean. Ophthalmic Res, 34:135-8.

Klais CM, Bühren J, Kohnen T. 2003. Comparison of endothelial cell count using confocal and contact specular microscopy. Ophthalmologica, 217:99-103.

Krik RW. 2005. Basic and clinical science course section 8 2004-2005; External disease and cornea. San Francisco: American Academy of Ophthalmology, p 32-3.

Laing RA, Sandstrom MM, Berropsi AR. 1976. Changes in corneal endothelium as a function of age. Exp Eye Res, 22:587-94.

Landesz M, Siertsema JV, Van Rij G. 1995. Comparative study of three semiautomated specular microscopes. J Cataract Refract Surg, 21:409-16.

Matsuda M, Yee RW, Edelhauser HF. 1985. Comparison of the corneal endothelium in an American and a Japanese population. Arch Ophthalmol, 103:68-70.

Padilla MD, Sibayan SA, Gonzales CS. 2004. Corneal endothelial cell density and morphology in normal Filipino eyes. Cornea, 23:129-35.

Rao SK, Ranjan SP, Fogla R, et al. 2000. Cornea endothelial cell density and morphology in normal Indian eyes. Cornea, 19:820-3.

Snellingen T, Rao GN, Shrestha JK, et al. 2001. Quantitative and morphological characteristics of the human corneal endothelium in relation to age, gender, andethnicity in cataract populations of south Asia Cornea, 20:55-8.

Zoega GM, Fujisawa A, Sasaki H, et al. 2006. Prevalence and risk factors for cornea guttata in the Reykjavik Eye study. Ophthalmology, 113:565-9. 
